\title{
Sensitivity to the generalized other with control for assimilative projection'
}

\author{
CLARRY HI. LAY ${ }^{2}$ and (;ORDON THOMPSON, Liniversity of \\ Manitoba, Winnipeg. Canada
}

Male and female judges predicted the response's of the generalized other to a number of personality stateme'nts. Judges were less accurate and less judgmentally certain when their self-response conflicted with the majority response. They were more accurate when predicting majority responses to high endorsement than to low endorsement frequency statements.

In the perception of the personality of others, the perceiver may tend to make his judgments consistent with the perceived nornt. The influence of this predisposition on predictive accuracy will of course depend on the veridicality of the perceived norm, as well as the digree of correspondence between the norm and the target criteria.

Bronfenbrenner, Harding, \& Gallwey (1958) assessed some of the correlates of the judge's ability to predict the norm. In addition, they made several somewhat unstccessful attempts to develop a "pure" measure of sensitivity to the generalized other which would be independent of the judge's similarity to the group being judged. This purity is important, particularly with extreme norms, since the more extreme the probability of occurrence or absence in others of a trait, the greater the likelihood that both the target person and the judge approach this norm (i.e.. that they are similar). In predicting the responses of the generalized other. the judge might be expected to be less accurate and less judgmentally certain where his own behavior is contrary to the norm.

The purpose of the present study was to examine the effects of (1) direction of the judge's own behavior in relation to the norm, thereby accounting for the effects of assimilative projection: (2) probability of occurrence of the behavior: and (3) sex of the judge on the accuracy of nomative predictions, and on judgmental certainty.

In the present study judges were asked to predict the responses of the generalized other to a number of personality statements. The advantages of this direct method of assessing normative judgments over the indirect method based on ratings of specific targets have been discussed by Bronfenbrenner et al (1958).

\section{SELF-RESPONSE QUESTIONNAIRE}

A self-response personality questionnaire was prepared containing statements drawn from the 20 content scales of the Personality Research Form (PRF-Jackson. 1967). The statements selected had either high (.75 to .95) or low (.10 to .25) endorsement proportions. In addition, all statements were neutral in desirability, these values based on item-desirability scale score biserial correlations. These statistics were based on datil gathered from male and female university students in the development of the PRF, and were made available by D. N. Jackson. There were 88 statements satisfying these requirements. Fifty-two filler items of moderate endorsement proportion were selected from the same 20 PRF scales. The order of these 140 items was randomly determined, but constant over Ss.

The questionnaire was administered under standard personality inventory instructions. Each $S$ completed the self-response questionnaire on two occasions separated by a one week interval.

\section{EXPERIMENTAL MATERIALS AND TASK}

For each $S$, statements which were consistently answered over the two test administrations in the direction opposite to their endorsement Irequency were used to prepare the individual S's prediction booklet. Ss with less than the arbitrarily set minimum of five anti-endorsement frequency statements were eliminated from the sample. The largest number of anti-endorsement responses for any one $\mathrm{S}$ was 10 . Thus the number of anti-endorsement statements per $S$ ranged from an arbitrary minimum of five to a maximum of 10 . In addition. statements were selected which had becol consistently answered in the :ndorsement frecuency direction (prorendorsement statements). These statements were matched for scale and endorsement frequency with the anti-endorsement statements. For some anti-endorsement statement no matching items from the same scale were available. In this case a pro-endorsement statement with similar endorsemint frequency was randomly selected from availible statements of other scales.

The order of the anti-endorsement and matched proendorsement prediction statements in the individual prediction booklets was random for each judge. The necessary number of filler statements was added so that each set of prediction statements consisted of 20 items.

The Ss were asked to predict how "the majority of university students in general". would answer the response statements. If they thought that the majority of university students (i.e., greater than $50 \%$ ) would answer a statement true, they were to circle the " $T$ " to the right of the statement; if they thought that the majority would answer the statement false, they were to circle the "F." They were also asked to indicate the degree of certainty of their judgments. In making their certainty ratings, the judges used a nine-point scalc ranging from "extremely uncertain" to "extremely certain."

The self-response questionnaires were presented during Sessions 1 and 2 which were one week apart. The individual prediction booklets were presented in the third session which followed the second by two weeks. The Ss were asked in each session to place their name and seat number on their booklets and to sit in the same seat each session. Booklets were distributed before the Ss entered the testing room and it was therefore possible to assign the appropriate individual prediction booklets without the Ss being aware that they had been individually prepared. Instructions were printed on the first page of each self-response questionnaire and prediction booklet. The $S s$ were encouraged to read the instructions carefully, and to ask questions whenever necessary.

\section{SUBJECTS}

The Ss were 28 male and 28 female university student volunteers participating for credit in an introductory psychology course. A greater number of Ss completed the questionnaires. Their number was first reduced by 25 , since these Ss had less than the arbitrary minimum of five anti-endorsement frequency self-responses, and further reduced by eight Ss who lacked suitable response statements in one or more of the experimental cells. Also, in order to obtain an equal number per cell, four females were randomly selected from the reduced sample and excluded from the final analysis.

\section{RESULTS}

The judge's predictions of the majority response were scored in terms of accuracy, an accurate judgment being one in the direction of the known endorsement frequency. Accuracy scores were derived for each $\mathrm{S}$ by dividing the number of accurate predictions by the total number of predictions made. ${ }^{3}$ The mean accuracy score for male and for female judges on pro-endorsement and anti-endorsement statements of high and low endorsement frequency is presented in Table 1 . As expected, accuracy scores were greater with pro-endorsement than with anti-endorsement statements $(F=14.0, \mathrm{df}=1,46, \mathrm{p}<.001)$. That is, judges more accurately predicted the majority response when they had responded in the endorsement frecuency direction themselves. Judges were also more accurate when predicting majority responses to high endorsement than to low endorsement frequency statements $(F=11.8, d f=1,46, p<.01)$.

The judgmental certainty ratings were assigned a value from one to nine. with the largest value representing extreme certainty. The mean certainty rating for nale and for female judges on pro-endorsement and anti-endorsement statements of high and low endorsement frequency is presented in Table 2. As expected. 
Table 1

Mean Accuracy Score for Male and Female Judges on Pro-Endorsement and Anti-Endorsement Statements of High and Low Endorsement Frequency

\begin{tabular}{|c|c|c|c|c|c|}
\hline & \multicolumn{4}{|c|}{ Endorsement Frequency } & \multirow[b]{3}{*}{ Total } \\
\hline & \multicolumn{2}{|c|}{ High } & \multicolumn{2}{|c|}{ Low } & \\
\hline & Male & Female & Male & Female & \\
\hline Pro-Endorsement & .88 & .89 & .75 & .62 & .78 \\
\hline Anti-Endorsement & .67 & .70 & .51 & .58 & .61 \\
\hline Total & .77 & .79 & .63 & .60 & \\
\hline
\end{tabular}

judges were more certain of their ratings on pro-endorsement than on anti-endorsement statements $(F=12.1$, df $=1,46, p<.001)$.

\section{DISCUSSION}

As expected, the judge's self-response tended to distort his perception of the group norm in the direction of assimilation. At the same time, the judge appeared to experience conflict on anti-endorsement statements, as reflected in his lower certainty. What must now be considered is the extent to which the assimilative projection judgment actually reflects a judgment made consistent with the perceived norm, albeit an inaccurately perceived norm distorted in the direction of self-response.

The greater accuracy on high than on low endorsement frequency statements may be due simply to the judge's tendency to predict "true," paralleling acquiescence found in self-responding. An alternative, more tentative interpretation may be considered, however. Judges may customarily view the attributes of others in terms of traits possessed, and may therefore be experientially less facile in making "uncharacteristic" judgments.
Table 2

Mean Judgmental Certainty Rating for Male and Female Judges on Pro-Endorsement and Anti-Endorsement Statements of High and Low Endorsement Frequency

\begin{tabular}{|c|c|c|c|c|c|}
\hline & \multicolumn{4}{|c|}{ Endorsement Frequency } & \multirow[b]{3}{*}{ Total } \\
\hline & \multicolumn{2}{|c|}{ High } & \multicolumn{2}{|c|}{ Low } & \\
\hline & Male & Female & Male & Female & \\
\hline Pro-Endorsement & 6.5 & 6.9 & 6.6 & 6.1 & 6.5 \\
\hline Anti-Endorsement & 6.1 & 6.0 & 5.9 & 6.0 & 6.0 \\
\hline Total & 6.3 & 6.4 & 6.2 & 6.0 & \\
\hline
\end{tabular}

\section{REFERENCES}

BRONFENBRENNER, U., HARDING, J., \& GALLWEY, M. The measurement of skill in social perception. In D. McClelland, A. Baldwin, $U$. Bronfenbrenner, and F. Strodtbeck (Eds.), Talent and society. Princeton, N. J.: Van Nostrand, 1958. Pp. 29-111.

JACKSON, D. N. Personality research form manual. Goshen, N.Y.: Research Psychologists Press, 1967.

\section{NOTES}

1. This research was supported in part by a grant to the first author from the Faculty of Graduate Studies and Research of the University of Manitoba.

2. Now at York University.

3. The number of prediction statements within each S's sample did not substantially influence accuracy scores or judgmental certainty, the Pearson Product-Moment correlations being -.15 and -.11 , respectively $(\mathrm{N}=224)$. 